\title{
High-density genome-wide association study for residual feed intake in Holstein dairy cattle
}

\author{
B. Li, ${ }^{1 *}$ L. Fang, ${ }^{1,2,3 *}$ D. J. Null, ${ }^{1}$ J. L. Hutchison, ${ }^{1}$ E. E. Connor, ${ }^{4}$ P. M. VanRaden, ${ }^{1}$ M. J. VandeHaar, ${ }^{5}$ \\ R. J. Tempelman, ${ }^{5}$ K. A. Weigel, ${ }^{6}$ and J. B. Cole ${ }^{1} \dagger$ \\ ${ }^{1}$ Animal Genomics and Improvement Laboratory, Agricultural Research Service, USDA, Beltsville, MD 20705-2350 \\ ${ }^{2}$ Department of Animal and Avian Sciences, University of Maryland, College Park 20742 \\ ${ }^{3}$ Medical Research Council Human Genetics Unit at the Medical Research Council Institute of Genetics and Molecular Medicine, \\ University of Edinburgh, Edinburgh, EH4 2XU, United Kingdom \\ ${ }^{4}$ Department of Animal and Food Sciences, University of Delaware, Newark 19716 \\ ${ }^{5}$ Department of Animal Science, Michigan State University, East Lansing 48824 \\ ${ }^{6}$ Department of Dairy Science, University of Wisconsin, Madison 53706
}

\section{ABSTRACT}

Improving feed efficiency (FE) of dairy cattle may boost farm profitability and reduce the environmental footprint of the dairy industry. Residual feed intake (RFI), a candidate FE trait in dairy cattle, can be defined to be genetically uncorrelated with major energy sink traits (e.g., milk production, body weight) by including genomic predicted transmitting ability of such traits in genetic analyses for RFI. We examined the genetic basis of RFI through genome-wide association (GWA) analyses and post-GWA enrichment analyses and identified candidate genes and biological pathways associated with RFI in dairy cattle. Data were collected from 4,823 lactations of 3,947 Holstein cows in 9 research herds in the United States. Of these cows, 3,555 were genotyped and were imputed to a high-density list of 312,614 SNP. We used a single-step GWA method to combine information from genotyped and nongenotyped animals with phenotypes as well as their ancestors' information. The estimated genomic breeding values from a single-step genomic BLUP were back-solved to obtain the individual SNP effects for RFI. The proportion of genetic variance explained by each 5-SNP sliding window was also calculated for RFI. Our GWA analyses suggested that RFI is a highly polygenic trait regulated by many genes with small effects. The closest genes to the top SNP and sliding windows were associated with dry matter intake (DMI), RFI, energy homeostasis and energy balance regulation, digestion and metabolism of carbohydrates and proteins, immune regulation, leptin signaling, mitochondrial

Received March 18, 2019.

Accepted July 19, 2019.

*These authors contributed equally to this work.

$\dagger$ Corresponding author: john.cole@ars.usda.gov
ATP activities, rumen development, skeletal muscle development, and spermatogenesis. The region of 40.7 to $41.5 \mathrm{Mb}$ on BTA25 (UMD3.1 reference genome) was the top associated region for RFI. The closest genes to this region, CARD11 and EIF3B, were previously shown to be related to RFI of dairy cattle and FE of broilers, respectively. Another candidate region, 57.7 to $58.2 \mathrm{Mb}$ on BTA18, which is associated with DMI and leptin signaling, was also associated with RFI in this study. Post-GWA enrichment analyses used a sumbased marker-set test based on 4 public annotation databases: Gene Ontology, Kyoto Encyclopedia of Genes and Genomes (KEGG) pathways, Reactome pathways, and medical subject heading (MeSH) terms. Results of these analyses were consistent with those from the top GWA signals. Across the 4 databases, GWA signals for RFI were highly enriched in the biosynthesis and metabolism of amino acids and proteins, digestion and metabolism of carbohydrates, skeletal development, mitochondrial electron transport, immunity, rumen bacteria activities, and sperm motility. Our findings offer novel insight into the genetic basis of RFI and identify candidate regions and biological pathways associated with RFI in dairy cattle.

Key words: feed efficiency, dairy cow, genome-wide association study, enrichment analysis

\section{INTRODUCTION}

Feed accounts for the largest part of operating costs in dairy production (European Commission, 2018; USDA, 2018). Improving feed efficiency (FE) of dairy cattle has the potential to increase farm profitability and reduce the environmental footprint of dairy production (VandeHaar et al., 2016). The widely recognized genetic variation in $\mathrm{FE}$ has created possibilities for improving FE of dairy cattle using genetics and breeding. Genetic 
studies of FE have been carried out in several dairy populations worldwide, covering some important topics including genetic parameter estimation (Berry et al., 2014; Li et al., 2018), genomic evaluation (de Haas et al., 2015; Pryce et al., 2015), and genome-wide association (GWA; Hardie et al., 2017; Lu et al., 2018). In addition, alternative $\mathrm{FE}$ definitions were investigated to appropriately define $\mathrm{FE}$ of dairy cattle in different populations (Lu et al., 2015; Pryce et al., 2015; Hurley et al., 2017; Li et al., 2017).

Residual feed intake (RFI), as one proposed FE definition trait, has been widely studied in pigs (Patience et al., 2015), chickens (Wolc et al., 2013), beef cattle (Crews, 2005), and dairy cattle (Berry and Crowley, 2013; Tempelman et al., 2015). Generally, RFI is defined as the difference between an animal's actual feed intake and its expected feed intake based on energy requirements for production and maintenance (Koch et al., 1963). In dairy cattle, RFI is calculated as the deviation of actual intake of a cow from the average intake of other cows that are fed and managed in the same way (cohort), after adjusting for major energy sinks [milk production, metabolic body weight (MBW), and change in BW $(\boldsymbol{\Delta} \mathbf{B W})$ ] (VandeHaar et al., 2016). The calculated RFI is phenotypically independent of energy sink traits (e.g., milk production, MBW) but may still be genetically correlated with these traits. $\mathrm{Lu}$ et al. (2015) applied a multiple-trait modeling method to define RFI in dairy cattle in order to derive RFI that was genetically uncorrelated with energy sink traits. VanRaden et al. (2018) developed an alternative method to derive RFI that was genetically uncorrelated with milk energy and body weight composite (BWC) by including genomic predicted transmitting ability (GPTA) of milk energy and GPTA of BWC in the genetic analyses for RFI. An RFI value that is genetically uncorrelated with major energy sink traits (e.g., milk yield, BW) is of interest because milk production traits and BWrelated traits are often part of the selection objectives in dairy cattle selection indices (Cole and VanRaden, 2018). After the removal of the genetic correlations of RFI with milk production and BW, RFI becomes a more independent trait representing $\mathrm{FE}$ in the selection index.

Defining RFI that is genetically independent from yield traits and BW could also improve understanding of the genetic basis of RFI in dairy cattle. Genome-wide association analysis is a useful tool for understanding the underlying biology of a trait by identifying genomic regions associated with genetic variation in traits, as well as identifying genes that may be associated with those traits (Cole et al., 2011). When RFI is defined as being genetically independent from energy sink traits, the GWA signals for RFI could be more associated with
RFI itself and free from the influence of milk yield and BW. In addition, previous GWA studies (GWAS) for RFI in lactating dairy cows were mostly carried out using medium-density (50-60k) SNP genotypes (Hardie et al., 2017; Lu et al., 2018). Applying high-density (HD) SNP chips for a GWAS may help to refine the candidate genomic regions for RFI and offer new insight into the genetic basis of RFI.

In this study, RFI was analyzed using the model of VanRaden et al. (2018), in which RFI was genetically uncorrelated with milk energy and BWC. The objectives were to understand the genetic basis for RFI using high-density genotypes and to identify candidate genes, biological processes, and pathways associated with RFI through GWA and post-GWA enrichment analyses.

\section{MATERIALS AND METHODS}

\section{Phenotypes}

The current study included 4,823 lactations of 3,947 Holstein cows. The cows were from 9 research herds in the central and eastern United States, including Iowa State University (Ames), University of Wisconsin-Madison, the USDA Animal Genomics and Improvement Laboratory (Beltsville, MD), University of Florida (Gainesville), the US Dairy Forage Research Center (Madison, WI), Michigan State University (East Lansing), the Purina Animal Nutrition Center (Gray Summit, MO), Virginia Polytechnic Institute and State University (Blacksburg), and the Dairy Research Facility at the Miner Institute (Chazy, NY). Data were collected between 2007 and 2016. The cows were in lactation 1 to lactation 8 , and the number of cows in each parity was $3,889,3,482,2,407,1,308,543$, 37,13 , and 2 , respectively. The calving age of the cows ranged from 19 to $94 \mathrm{mo}$, with an average of $40 \mathrm{mo}$. Pedigree information included 42,057 animals going back as many generations as possible for all animals with records.

The cows were involved in 44 experiments in the 9 research herds. The experimental designs and ingredients of diets in these experiments were described in detail previously (Ferraretto et al., 2012; He et al., 2012; Spurlock et al., 2012; Connor et al., 2013; Tempelman et al., 2015; Manzanilla-Pech et al., 2016). In general, the studied cows were fed TMR, and feed intakes were measured using electronic feeding systems. The experimental designs varied from single-ration studies dedicated only to FE genetic studies, to randomized designs, simple crossover designs, and multiple-treatment Latin square designs (Tempelman et al., 2015).

Daily DMI and milk yield, weekly or biweekly BW, and milk composition were recorded for each cow. Only 
measurements collected between 50 and 200 DIM were used and edited to form one 28-d average phenotype for DMI, milk energy, MBW, and $\triangle \mathrm{BW}$ (Tempelman et al., 2015). Energy sinks of milk energy, MBW, $\triangle \mathrm{BW}$, and several environmental effects were removed from DMI to obtain RFI records from previous studies (Tempelman et al., 2015). Most RFI records were from 6 -wk trials, but 202 records were from 4 -wk trials. The records from 4 -wk trials were given less weight (weight $\left.=0.96^{2}=0.92\right)$ in the genetic analyses because the standard deviation was higher in 4-wk trials than 6 -wk trials ( 1.75 vs. $1.68 \mathrm{~kg} / \mathrm{d})$ and the correlation of $4-$ and 6 -wk trials was 0.96 .

\section{Genotypes}

High-density genotypes were used in this study, including 312,614 SNP spanning the entire bovine genome. The 312,614-SNP panel was derived from $777 \mathrm{k}$ Illumina BovineHD Genotyping BeadChip (Illumina Inc., San Diego, CA) genotypes after editing for linkage disequilibrium, minor allele frequency, Hardy-Weinberg equilibrium, and Mendelian errors, using the same method as Wiggans et al. (2016). Of the 3,947 cows with phenotypes, 3,555 cows were genotyped, including 502 on the HD panel; the remaining 3,053 were imputed to HD as part of a larger study that included 2,394 HD genotypes and 592,757 genotyped Holsteins (VanRaden et al., 2017). Of the 42,057 animals in the pedigree, 6,151 were genotyped, including genotyped cows with phenotype information as well as genotyped sires and other ancestors in the pedigree. In the quality control process, animals and SNP with call rates $<0.90$, SNP with minor allele frequency $<0.05$, monomorphic SNP, SNP deviating from Hardy-Weinberg equilibrium expectation, and animals with parent-progeny Mendelian conflicts were omitted from the data set, using the preGSf90 program (version 1.10; Misztal, 2013). After data filtering, genotypes of 278,524 SNP from 5,610 genotyped individuals in the pedigree remained in the data set.

\section{GWA Analyses}

A single-step GWAS method (ssGWAS) proposed by Wang et al. (2012) was used to combine information from genotyped and nongenotyped animals with phenotypes as well as their ancestors' information into GWA analyses. In ssGWAS, a single-step genomic BLUP was first done to estimate genomic breeding values (GEBV) for all animals in the pedigree by combining their pedigree and genomic information. The model for single-step genomic BLUP analyses for RFI was as follows:

$$
\begin{gathered}
\mathrm{y}=\text { Age-parity-grp }+\mathrm{b}_{1} \times\left(\text { GPTA }_{\text {milk net energy }}\right) \\
+\mathrm{b}_{2} \times\left(\text { GPTA }_{\mathrm{BWC}}\right)+a+p e+e,
\end{gathered}
$$

where $\mathrm{y}$ is the RFI phenotype adjusted for energy sinks of milk yield, MBW, $\triangle \mathrm{BW}$ by phenotypic regressions, and several environmental effects, according to Tempelman et al. (2015); Age-parity-grp is the fixed effect of

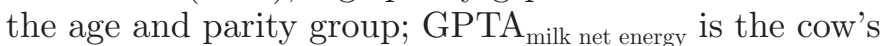
GPTA for milk net energy and GPTA ${ }_{\mathrm{BWC}}$ is the cow's GPTA for BWC, where the GPTA values for the studied cows were obtained from the US national genomic evaluation database for milk net energy and BWC; GPTA $_{\text {milk net energy }}$ and GPTA $_{\mathrm{BWC}}$ were included to remove the remaining genetic correlations of RFI with milk production and $\mathrm{BW}$ that were not completely removed by the phenotypic regressions; $b_{1}$ is the regression coefficient of cow's RFI on GPTA of milk net energy, which was different from $0(P<0.05) ; b_{2}$ is the regression coefficient of cow's RFI on GPTA of BWC, which was not significantly different from $0 ; a$ is the random additive genetic effect with $\operatorname{var}(a) \sim N\left(0, \mathbf{H} \sigma_{a}^{2}\right)$, where $\sigma_{a}^{2}$ is the additive genetic variance and $\mathbf{H}$ is the relationship matrix incorporating pedigree and genomic information as defined in Legarra et al. (2009); pe is the random permanent environmental effect to account for repeated measurements from an animal, with $\operatorname{var}(p e) \sim N\left(0, \mathbf{I} \sigma_{p e}^{2}\right)$, where $\sigma_{p e}^{2}$ is the permanent environmental variance and $\mathbf{I}$ is the identity matrix; and $e$ is the random residual with $\operatorname{var}(e) \sim N\left(0, \mathbf{R} \sigma_{e}^{2}\right)$, where $\sigma_{e}^{2}$ is the residual error variance and $\mathbf{R}$ is a diagonal matrix to adjust for the residual variance of each record based on their weights. Almost all RFI records were from 6 -wk trials, whereas 202 records were from 4 -wk trials. The records from 4 -wk trials were given less weight (weight $=0.92$ ), as described earlier in this article. Therefore, the diagonals of the $\mathbf{R}$ matrix are mostly 1 for records from 6 -wk trials and 1/0.92 for records from 4 -wk trials.

The variance components for RFI were estimated by an average information-restricted maximum likelihood algorithm using pedigree information, implemented in the airemlf90 program (version 1.134; Misztal, 2013). The estimated variance components were then applied to single-step genomic prediction implemented by the program blupf90 (version 1.58; Misztal, 2013). The GEBV were estimated for all animals in the pedigree by combining their pedigree and genomic information, and the inverse of the relationship matrix was as follows:

$$
\mathbf{H}^{-1}=\mathbf{A}^{-1}+\left[\begin{array}{cc}
0 & 0 \\
0 & \mathbf{G}^{-1}-\mathbf{A}_{22}^{-1}
\end{array}\right],
$$


where $\mathbf{G}^{-1}$ is the inverse of the genomic relationship matrix and $\mathbf{A}_{22}^{-1}$ is the inverse of the pedigree-based relationship matrix for genotyped animals. $\mathbf{G}$ was calculated as $\mathbf{G}={ }_{\mathrm{w}} \mathbf{G r}+(1-\mathrm{w}) \mathbf{A}_{\mathbf{2 2}}$ (Forni et al., 2011), where $\mathrm{w}=0.95$ and $\mathbf{G r}$ is a genomic matrix before weighting calculated as VanRaden (2008).

In the next step, GEBV were back-solved to obtain the SNP effects for RFI implemented by the program postGSf90 (version 1.46) (Wang et al., 2012). The program assumes that the markers explain $100 \%$ of the genetic variance in the back-solving process (Wang et al., 2012). The absolute values of estimated SNP effects were divided by the empirical standard deviation of estimated SNP effects to obtain standardized SNP effects. In addition to the single-marker estimates, a 5-SNP sliding window (average window size $38.4 \mathrm{~kb}$ ) was also constructed to calculate the proportion of genetic variance explained by 5 -SNP sliding windows. In the postGSf90 program, the proportion of genetic variance explained by each sliding window was calculated by the variance explained by the window divided by the total genetic variance (Wang et al., 2014), as follows:

$$
\frac{\operatorname{var}\left(a_{i}\right)}{\sigma_{a}^{2}} \times 100 \%=\frac{\operatorname{var}\left(\sum_{j=1}^{5} \mathbf{Z}_{i j} \hat{u}_{i j}\right)}{\sigma_{a}^{2}} \times 100 \%,
$$

where $a_{i}$ is genetic value of the $i$ th sliding window that consists of contiguous $5 \mathrm{SNP}$; $\operatorname{var}\left(a_{i}\right)$ is the genetic variance explained by the $i$ th sliding window; $\sigma_{a}^{2}$ is the total genetic variance obtained from the variance component estimate for RFI; $\mathbf{Z}_{i j}$ is the vector of gene content of the $j$ th SNP for all individuals in the $i$ th window; and $\hat{u}_{i j}$ is the estimate of marker effect of the $j$ th SNP within the ith window.

\section{GWA Signal Enrichment Analyses}

For the public annotation databases, $\mathrm{R}$ packages of org.Bt.eg.db (version 3.6.0), reactome.db (version 1.64.0), and MeSH (version 1.10.0) as distributed in Bioconductor (version 3.7) (https://www.bioconductor .org/) were used to obtain Gene Ontology (GO) terms, Kyoto Encyclopedia of Genes and Genomes (KEGG) pathways, Reactome pathways, and medical subject heading (MeSH) terms (Morota et al., 2015), respectively. The biological terms or pathways with fewer than 10 genes were excluded, so that each term or pathway contained at least 10 genes for analyses. In total, 898 GO terms, 225 KEGG pathways, 820 Reactome pathways, $436 \mathrm{MeSH}$ terms, and 248 trait-related terms were available for enrichment analyses.
A SNP was considered associated with one biological term or pathway if the SNP is located within $\pm 10 \mathrm{~kb}$ of genes in the term or pathway. Then, the enrichment of GWA signals in each term or pathway was tested using the effects of the SNP associated with the term or pathway. A marker-set test method was applied to the enrichment analyses (Rohde et al., 2016; Fang et al., 2017), implemented by the $\mathrm{R}$ package for Quantitative Genetic and Genomic analyses (Rohde et al., 2018). The summary statistics $\left(T_{\text {sum }}\right)$ for each term or pathway was calculated as follows using the SNP effects associated with each term or pathway:

$$
T_{\text {sum }}=\sum_{i=1}^{m_{f}} t^{2}
$$

where $T_{\text {sum }}$ is the summary statistics for each biological term or pathway; $t$ is the standardized SNP effect (i.e., absolute value of estimated SNP effect divided by the standard deviation of estimated SNP effects) of the SNP associated with each term or pathway; and $m_{f}$ is the number of SNP that are associated with each term or pathway.

The degree [i.e., $-\log _{10}(P$-value $\left.)\right]$ of enrichment of GWA signals in each term or pathway was then determined by a 10,000-times permutation test for $T_{\text {sum }}$ of each term or pathway. The empirical $P$-value for each term or pathway was calculated as the proportion of random $T_{\text {sum }}$ from permutation greater than the observed $T_{\text {sum }}$ (Rohde et al., 2016; Fang et al., 2017).

\section{RESULTS AND DISCUSSION}

\section{GWA Signals for RFI}

Residual feed intake was genetically regulated by many small-sized effects, indicating that RFI is a highly polygenic trait in dairy cattle (Figure 1a). Our findings in this study were consistent with previous GWAS for RFI in which no large peaks were observed for RFI in single-marker GWA analyses (Hardie et al., 2017; Lu et al., 2018). The 20 SNP with the highest standardized genetic effects for RFI are rich in BTA25 and BTA18 and were also observed in BTA1, 5, 9, 11, 14, 16, and 22 (Table 1). The top SNP for RFI are all common variants based on their minor allele frequencies (Table 1). Of the top $20 \mathrm{SNP}, 13$ are only available in the HD genotype and not within the standard genomic evaluation set of 60,671 SNP markers (Wiggans et al., 2016), implying some benefit of using denser markers for GWAS on RFI. The genes located closest to the top SNP are related to DMI and RFI, digestion and 

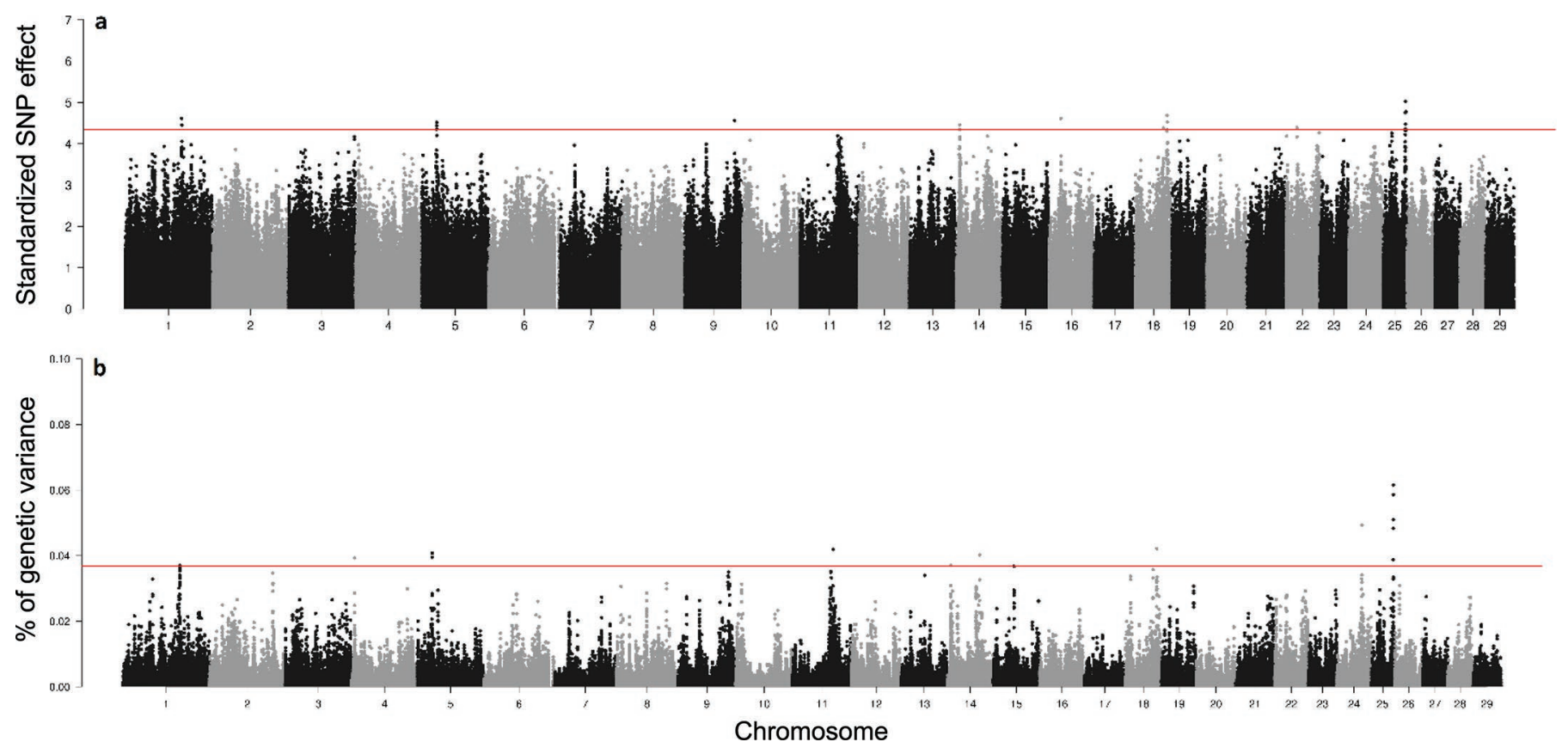

Figure 1. Manhattan plot of (a) the standardized SNP effect for residual feed intake (RFI), (b) the genetic variance (\%) explained by each 5-SNP sliding window (average window size $38.4 \mathrm{~kb}$ ) for RFI in Holstein dairy cattle. The horizontal line in (a) shows the threshold of the top $20 \mathrm{SNP}$ with the largest standardized effects for RFI, and the horizontal line in (b) is the threshold of the top 20 SNP explaining the largest genetic variance for RFI.

metabolism of carbohydrates and proteins, immune regulation, and mitochondrial ATP activities (Table 1).

The strongest SNP effects for RFI were clustered in the region of 40.7 to $41.5 \mathrm{Mb}$ on BTA25 (UMD3.1 reference genome), close to the CARD11 and EIF3B genes. The $C A R D 11$ (caspase recruitment domain family member 11) gene is a protein coding gene in Bos taurus, and its homolog in humans is widely reported to be associated with peripheral B-cell differentiation and a variety of critical T-cell effector functions (Stepensky et al., 2013; Ma et al., 2017). For FE in dairy cattle, Salleh et al. (2017) reported several immune genes and pathways associated with RFI in Danish Holstein cattle, among which $C A R D 11$ gene was found to be downregulated in animals with high RFI compared with those with low RFI. The EIF3B gene is a protein-coding gene related to the initiation of protein synthesis (Lee et al., 2015). The protein expression of EIF3B gene was upregulated in broilers with high $\mathrm{FE}$ ( $\mathrm{FE}=\mathrm{BW}$ gain/feed intake) (Kong et al., 2016).

Apart from the signals on BTA25, top effects for RFI were also rich in the region of 57.7 to $58.2 \mathrm{Mb}$ on BTA18. This candidate QTL region for RFI overlaps with a QTL region for DMI on BTA18 (Lu et al., 2018) and is also close to a QTL region affecting several calving and type traits in dairy cattle (Cole et al., 2009). Because RFI is mathematically defined from
DMI, it seems likely that QTL associated with DMI also influence RFI. The potential link among cows' RFI, DMI, sizes, and calving traits on BTA18 could be further studied by calculating regional genetic correlations between these traits for this particular region on BTA18. In addition, the top SNP in this candidate QTL region on BTA18 for RFI falls into the VSIG10L gene (V-set and immunoglobulin domain containing 10 like), a protein-coding gene highly expressed in the normal esophagus with a putative role in maintaining healthy esophageal homeostasis in humans (Fecteau et al., 2016).

\section{Variance in RFI Explained by Sliding Windows}

The proportion of genetic variance explained by 5-SNP sliding windows is shown in Figure 1b. Each sliding window explained a small proportion of genetic variance for RFI, with the highest variance explained by 5 -SNP sliding windows being $<1 \%$. The 20 sliding windows that explained the largest variance for RFI were observed in BTA25, 24, 18, 11, 5, 4, 14, 1, and 15 (Table 2). Most of the top SNP detected in the earlier single-marker GWA analysis were found within or close to these top sliding windows. The genes overlapping with, or closest to, these top windows were associated with DMI and RFI, energy homeostasis and energy 


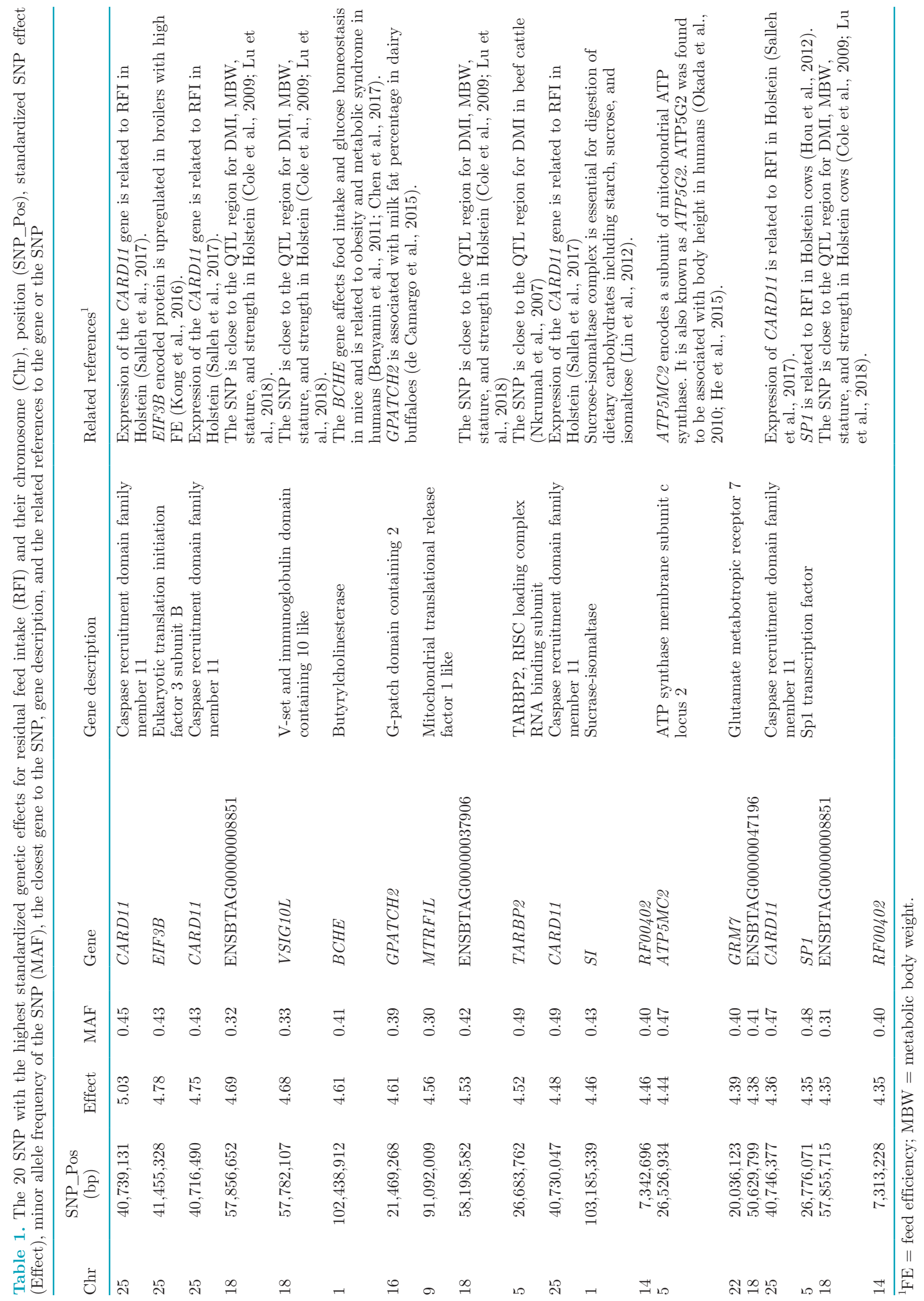


balance regulation, immune regulation, rumen development, skeletal muscle development, and spermatogenesis (Table 2).

In general, among all genes residing in or near the top sliding windows for RFI, several (C5H12orf10, PFDN5, CALCA, SDK1) were found to be related to RFI itself or to energy intake, and several genes (e.g., DNMT3A, MFSD5) are related to energy balance regulation (Table 2). These findings imply a general association of energy utilization and balance with RFI in dairy cows. A strong and positive genetic correlation was reported between RFI and energy balance in dairy cattle (Liinamo et al., 2015; Hurley et al., 2017), in agreement with our findings of a genetic association of energy balance with RFI.

Similar to earlier findings in the single-marker GWA analysis, the window that explains the highest genetic variance for RFI spans 40.71 to $40.77 \mathrm{Mb}$ on BTA25 (Figure 1; Table 2). The closest gene to this window, CARD11, is related to immune regulation and was related to RFI in dairy cattle (Salleh et al., 2017), as discussed earlier in the single-marker GWA analysis. The region of 57.81 to $57.86 \mathrm{Mb}$ on BTA18 was also seen among the top windows, in agreement with single-marker GWA results. In addition, the top sliding windows of 57.81 to $57.86 \mathrm{Mb}$ on BTA18 and 45.93 to $46.05 \mathrm{Mb}$ on BTA24 are found to overlap with SIGLEC10 (sialic acid binding Ig-like lectin-10) gene and SIGLEC15 gene, respectively. The SIGLEC10 and SIGLEC15 genes are members of the SIGLEC family of immune regulatory receptors (von Gunten and Bochner, 2008; Bornhöfft et al., 2018), and several members of the SIGLEC gene family (e.g., SIGLEC6, SIGLEC5) are known to bind to leptin (Patel et al., 1999). Leptin is widely recognized in the regulation of food intake, energy expenditure, fat distribution, whole-body energy balance, glucose homeostasis, and reproduction in rodents and humans (Houseknecht et al., 1998; Carter et al., 2013). In dairy cattle, Ehrhardt et al. (2016) reported that increased plasma leptin attenuates adaptive metabolism (e.g., mobilization of endogenous reserves) in early-lactating dairy cows. Based on our current findings, leptin and SIGLEC-family genes may play a role in regulating RFI and FE in dairy cattle.

\section{GWA Signal Enrichment}

The top biological terms or pathways highly enriching GWA signals for RFI are shown in Figure 2. Across the 4 annotation databases, GWA signals for RFI were highly enriched in the biosynthesis and metabolism of amino acids and proteins, digestion and metabolism of carbohydrates, skeletal development, mitochondrial electron transport, immunity, rumen bacteria activities, and sperm motility. These results are highly consistent with earlier findings in the top SNP or sliding windows. Overall, RFI was found to be related to diverse biological processes and pathways, suggesting RFI is a highly polygenic trait regulated by many genes.

More specifically, GWA signals for RFI were highly enriched in genes associated with digestion and metabolism of carbohydrates and proteins in all annotation databases, including carbohydrate digestion and absorption, gluconeogenesis, biosynthesis of various amino acids, and clathrin-coated vesicle activity. This finding indicates a systematic influence of energy metabolism on regulating FE estimated using RFI. In addition, the GWA signals for RFI were also highly enriched in skeletal development, including skeletal muscle cell differentiation (from GO), biosynthesis and metabolism of keratan sulfate (from both KEGG and Reactome), transforming growth factor- $\beta$ (TGF- $\beta$ ) signaling, and SMAD activities (from Reactome). The biosynthesis of keratan sulfate was the top pathway related to RFI in both KEGG and Reactome pathways. Keratan sulfate, as a complex glycosaminoglycan, is observed in diverse tissues and is an important component of cartilage and bone matrix (Wendel et al., 1998; Funderburgh, 2000). The TGF- $\beta$ signaling and SMAD proteins play key roles in body development and regulate the composition of bone matrix and bone architecture (Derynck and Zhang, 2003; Balooch et al., 2005).

Mitochondrial electron activity is another top enrichment term related to RFI, including mitochondrial electron transport, NADH to ubiquinone (from GO), and the pathway of ubiquinone and other terpenoidquinone biosynthesis (from KEGG). The association of RFI with mitochondrial ATP activity was also observed previously from the top GWA signals. Recent studies in poultry (Bottje et al., 2006) and in beef cattle (Kolath et al., 2006) provided evidence of a link between inefficient mitochondrial respiration and decreased FE. In Angus steers, steers with low RFI exhibited a greater rate of mitochondrial respiration than those with high RFI (Kolath et al., 2006). In broilers, mitochondria obtained from inefficient broilers exhibited greater uncoupling of the electron transport chain and greater oxidative stress compared with efficient broilers (Bottje et al., 2006; Bottje and Kong, 2013).

In addition, terms or pathways associated with immunity (Toll-Like Receptors Cascades from Reactome), rumen bacterial activities (Ruminants and bacteria from MeSH, Porphyrin and chlorophyll metabolism from KEGG), and sperm motility (from KEGG) were also enriching GWA signals for RFI. The associations between RFI with immunity and with rumen bacterial activities were observed earlier in our top sliding windows and also in the recent literature (Jewell et al., 


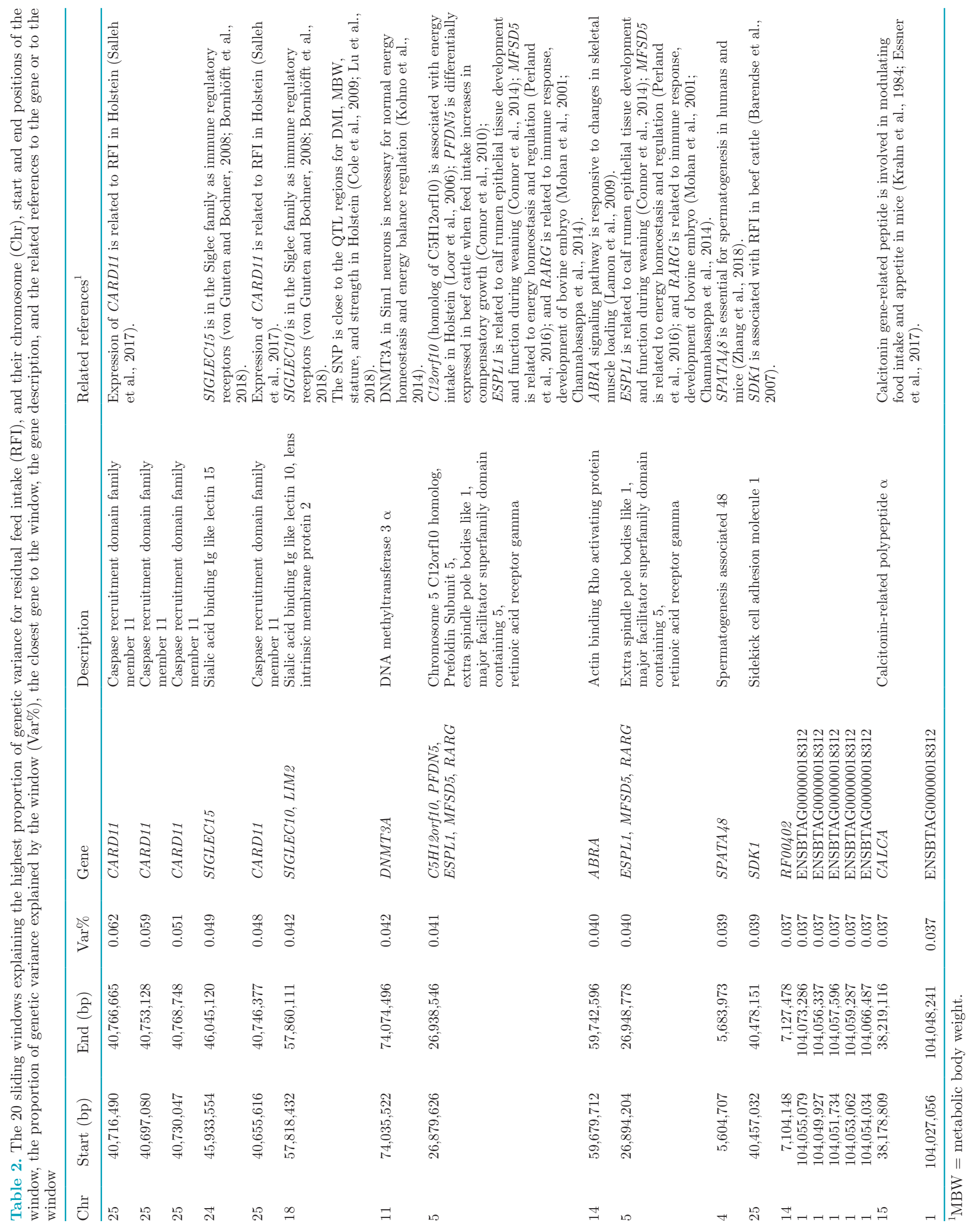


2015; Salleh et al., 2017; Elolimy et al., 2018). Studies also reported that beef bulls with lower RFI have decreased sperm motility and sperm viability compared with the inefficient beef bulls, indicating an undesirable effect of selection for improved FE on reproduction in beef cattle (Awda et al., 2013; Fontoura et al., 2016). However, the genetic correlation between RFI and fertility of dairy cattle remains unclear. In dairy cattle, studies indicate genetic correlation between residual energy intake and energy balance (Liinamo et al., 2015), and negative energy balance in cows has been reported to have unfavorable effect on fertility (e.g., Banos and Coffey, 2010). However, the direct estimation of genetic correlation between RFI and cow fertility has very rarely been studied. Assessing accurate genetic correlation between RFI and fertility in dairy cattle is highly recommended in future genetic studies for FE. It is also worth noting that the estimates of genetic correlation between RFI and other traits can be affected by the methods used to model RFI (e.g., different energy sink traits included in the RFI model).

\section{GWA Using the Single-Step Method}

Genome-wide association analyses can be conducted using various methodologies (Wang et al., 2012; Hayes,

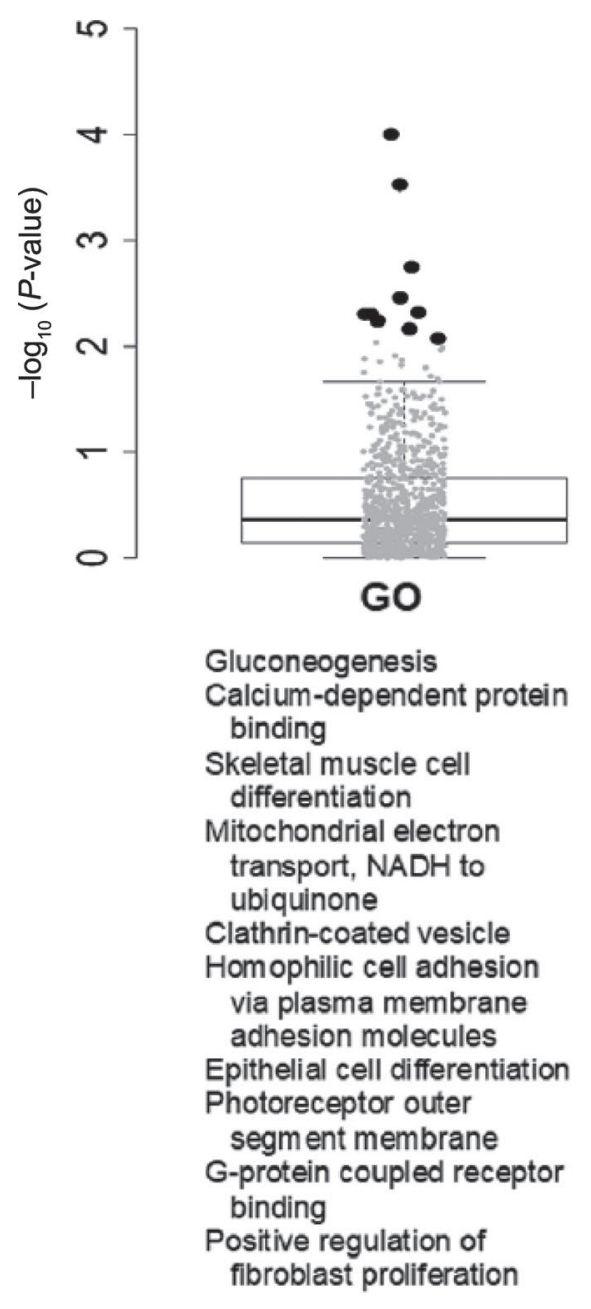

Figure 2. The top biological terms and pathways highly enriching genome-wide association (GWA) signals for residual feed intake (RFI). Each dot in the boxplot represents one tested term or pathway in 4 public gene annotation databases of 898 Gene Ontology (GO) terms, 225 Kyoto Encyclopedia of Genes and Genomes (KEGG) pathways, 820 Reactome pathways, and 436 medical subject heading (MeSH) terms. The degree [i.e., $-\log _{10}(P$-value $\left.)\right]$ of GWA signal enrichment in each term or pathway was determined by a 10,000 -times permutation test for the summary statistics $\left(\mathrm{T}_{\mathrm{sum}}\right)$ of each term or pathway. The top 10 biological terms or pathways enriching GWA signals of RFI are shown as black dots in a boxplot and are tabulated under the boxplot for each annotation database. The midline, box edges, the upper bound and lower bound lines of each boxplot represent median, interquartile range (IQR), third quartile $+1.5 \times$ IQR, and first quartile $-1.5 \times$ IQR, respectively. 
2013; Schmid and Bennewitz, 2017), including classical single-marker regressions, Bayesian methods, and ssGWAS, as applied in this study. In single-marker regressions, the level of multiple testing can be enormous with dense SNP data, and stringent thresholds are needed to prevent an inflation of type-I errors (Schmid and Bennewitz, 2017). The GWA analyses using Bayesian methods or ssGWAS evaluate all SNP simultaneously, considering that the effect of a gene is only partly captured by a single marker due to imperfect linkage disequilibrium but might be better explained jointly by multiple SNP surrounding the gene (Hayes, 2013; Schmid and Bennewitz, 2017). In the ssGWAS used in this study, all phenotypic information from genotyped and ungenotyped animals, as well as their ancestors' information, was used simultaneously through joint genomic and pedigree information. The main advantage of ssGWAS is the ability to incorporate phenotypes of ungenotyped subjects directly in the association analyses without the need to construct pseudo-observations (Wang et al., 2012). Therefore, ssGWAS could be more useful when a large number of phenotyped subjects are not genotyped or when obtaining accurate pseudodata (e.g., de-regressed proofs) is difficult (Wang et al., 2014).

In Bayesian analyses or single-marker regressions, information from nongenotyped animals can be indirectly included in the association in multistep procedures using de-regressed proofs. In our previous study (unpublished data), an approximate BayesA method was applied to estimate GEBV and SNP effects for RFI using the same data set as this study, but with 60,671 SNP markers. The SNP that explained the largest genetic variances for RFI from the BayesA analysis agree with those found in this study using ssGWAS. The top SNP for RFI found from BayesA and from ssGWAS were identical, on BTA25 in the region of 40.7 to $41.5 \mathrm{Mb}$. A more comprehensive comparison between ssGWAS and Bayesian method for GWA analyses was described by Wang et al. (2012, 2014), who compared ssGWAS and BayesB for GWAS through a simulation study and a real-data study in chicken. Their results showed that ssGWAS and BayesB delivered similar predictions of QTL, but the magnitude of SNP effect estimates can be very different due to the different assumptions in the distribution of SNP effect and variance (Wang et al., 2012, 2014).

A limitation of the current study using ssGWAS is that it assumes equal variance for all SNP effects, which may not be accurate in all cases. One way to offset this limitation is to relax this assumption through combining single-step method with Bayesian framework. However, the cost of computing time in such a method would also need to be considered. In addition, a proper significance test for SNP effects needs to be implemented in ssGWAS. In the current version of postGSf90 program used in this study, a standardized SNP effect was calculated to account for the empirical standard deviation of estimated SNP effects. A significance test in ssGWAS is under development in a new version of postGSf90 program, so that $P$-value test statistics could be applied to future genomic association analyses using ssGWAS.

\section{Genomic Prediction for RFI}

Residual feed intake is regulated by many small-sized effects and is related to diverse biological processes and pathways. Despite the complexity of the genetic basis of RFI, RFI is still a promising FE candidate trait in dairy cattle breeding, considering its independence of other index traits. In this study, GPTA of energy sink traits was included in the genetic model of RFI, so that RFI was genetically uncorrelated with major energy sink traits (milk production, BWC) in the selection indexes. The heritability of RFI was estimated to be 0.14 in our data set (VanRaden et al., 2018). The SNP of importance detected from this study could be used to provide weight information to the SNP used for future genomic prediction for RFI. Minor allele frequencies of the top SNP in this study indicated that the top SNP for RFI were common variants, indicating the potential of applying genomic selection to RFI given the variation.

\section{CONCLUSIONS}

Residual feed intake can be defined to be genetically uncorrelated with major energy sink traits (e.g., milk production, BW), by including animals' GPTA of these energy sink traits in the genetic analyses for RFI. Based on our GWA analysis and post-GWA enrichment analyses, RFI was a highly polygenic trait regulated by many small-sized effects. Residual feed intake was related to diverse biological processes and pathways, including DMI, energy balance, carbohydrate and protein metabolism, skeletal development, mitochondrial energy generation, leptin signaling, immunity, rumen bacteria activities, and sperm motility. The region of 40.7 to $41.5 \mathrm{Mb}$ on BTA25 was the top associated region for RFI, with the closest gene to this region (CARD11) being related to immune regulation and having been reported to be related to RFI in dairy cattle. The region of 57.7 to $58.2 \mathrm{Mb}$ on BTA18, which is associated with leptin signaling and DMI, was also associated with RFI in this study. Despite the complexity of the genetic basis of RFI, RFI is still a promising FE candidate 
trait in dairy cattle breeding, with genomic selection as an important tool in selecting for FE in dairy cattle. The SNP of importance detected from this study could be used to provide weight information to the SNP for future genomic prediction for RFI.

\section{ACKNOWLEDGMENTS}

J. B. Cole, D. J. Null, J. L. Hutchison, and P. M. VanRaden were supported by appropriated project 8042-31000-002-00-D, "Improving Dairy Animals by Increasing Accuracy of Genomic Prediction, Evaluating New Traits, and Redefining Selection Goals," and E. E. Connor was supported by appropriated project 8042-31310-078-00-D, "Improving Feed Efficiency and Environmental Sustainability of Dairy Cattle through Genomics and Novel Technologies," of the Agricultural Research Service (ARS) of the USDA. B. Li was supported in part by an appointment to the ARS Research Participation Program, administered by the Oak Ridge Institute for Science and Education through an interagency agreement between the U.S. Department of Energy and ARS. L. Fang was supported in part by AFRI grant numbers 2013-67015-20951, 2016-67015-24886, and 2019-67015-29321 from the USDA National Institute of Food and Agriculture (NIFA; Washington, DC) Animal Genome and Reproduction Programs. R. J. Tempelman, M. J. VandeHaar, and K. A. Weigel were supported in part by Agriculture and Food Research Initiative Competitive Grant \#2011-68004-30340 from NIFA. The Council on Dairy Cattle Breeding (Bowie, MD), Cooperative Dairy DNA Repository (Verona, WI), and other dairy industry contributors are thanked for providing pedigree and genomic data. Mention of trade names or commercial products in this article is solely for the purpose of providing specific information and does not imply recommendation or endorsement by the USDA. The USDA is an equal opportunity provider and employer. Two anonymous reviewers are thanked for their comments and suggestions, which greatly improved the quality of the manuscript.

\section{REFERENCES}

Awda, B. J., S. P. Miller, Y. R. Montanholi, G. Vander Voort, T. Caldwell, M. M. Buhr, and K. C. Swanson. 2013. The relationship between feed efficiency traits and fertility in young beef bulls. Can. J. Anim. Sci. 93:185-192. https://doi.org/10.4141/cjas2012-092.

Balooch, G., M. Balooch, R. K. Nalla, S. Schilling, E. H. Filvaroff, G. W. Marshall, S. J. Marshall, R. O. Ritchie, R. Derynck, and T. Alliston. 2005. TGF- $\beta$ regulates the mechanical properties and composition of bone matrix. Proc. Natl. Acad. Sci. USA 102:1881318818.

Banos, G., and M. P. Coffey. 2010. Genetic association between body energy measured throughout lactation and fertility in dairy cattle. Animal 4:189-199. https://doi.org/10.1017/S1751731109991182.
Barendse, W., A. Reverter, R.J. Bunch, B.E. Harrison, W. Barris, and M.B. Thomas. 2007. A validated whole-genome association study of efficient food conversion in cattle. Genetics 176:1893-1905. https://doi.org/10.1534/genetics.107.072637.

Benyamin, B., R. P. Middelberg, P. A. Lind, A. M. Valle, S. Gordon, D. R. Nyholt, S. E. Medland, A. K. Henders, A. C. Heath, P. A. F. Madden, P. M. Visscher, D. T. O'Connor, G. W. Montgomery, N. G. Martin, and J. B. Whitfield. 2011. GWAS of butyrylcholinesterase activity identifies four novel loci, independent effects within BCHE and secondary associations with metabolic risk factors. Hum. Mol. Genet. 20:4504-4514. https://doi.org/10.1093/ $\mathrm{hmg} / \mathrm{ddr} 375$.

Berry, D. P., M. P. Coffey, J. E. Pryce, Y. de Haas, P. Løvendahl, N. Krattenmacher, J. J. Crowley, Z. Wang, D. Spurlock, K. Weigel, K. Macdonald, and R. F. Veerkamp. 2014. International genetic evaluations for feed intake in dairy cattle through the collation of data from multiple sources. J. Dairy Sci. 97:3894-3905. https://doi .org/10.3168/jds.2013-7548.

Berry, D. P., and J. J. Crowley. 2013. Cell Biology Symposium: Genetics of feed efficiency in dairy and beef cattle. J. Anim. Sci. 91:1594-1613. https://doi.org/10.2527/jas.2012-5862.

Bornhöfft, K. F., T. Goldammer, A. Rebl, and S. P. Galuska. 2018. Siglecs: A journey through the evolution of sialic acid-binding immunoglobulin-type lectins. Dev. Comp. Immunol. 86:219-231. https://doi.org/10.1016/j.dci.2018.05.008.

Bottje, W., and B.-W. Kong. 2013. Cell Biology Symposium: Feed efficiency: Mitochondrial function to global gene expression. J. Anim. Sci. 91:1582-1593.

Bottje, W., N. R. Pumford, C. Ojano-Dirain, M. Iqbal, and K. Lassiter. 2006. Feed efficiency and mitochondrial function. Poult. Sci. 85:8-14.

Carter, S., A. Caron, D. Richard, and F. Picard. 2013. Role of leptin resistance in the development of obesity in older patients. Clin. Interv. Aging 8:829-844. https://doi.org/10.2147/CIA.S36367.

Channabasappa, S., J. Ferguson, and B. Singh. 2014. Expression of retinoid receptors in lungs of cattle, dogs, and pigs. Can. J. Vet. Res. 78:176-182.

Chen, V. P., Y. Gao, L. Geng, and S. Brimijoin. 2017. Butyrylcholinesterase regulates central ghrelin signaling and has an impact on food intake and glucose homeostasis. Int. J. Obes. (Lond.) 41:1413-1419. https://doi.org/10.1038/ijo.2017.123.

Cole, J. B., and P. M. VanRaden. 2018. Symposium review: Possibilities in an age of genomics: The future of selection indices. J. Dairy Sci. 101:3686-3701. https://doi.org/10.3168/jds.2017-13335.

Cole, J. B., P. M. VanRaden, J. R. O'Connell, C. P. van Tassell, T. S. Sonstegard, R. D. Schnabel, J. F. Taylor, and G. R. Wiggans. 2009. Distribution and location of genetic effects for dairy traits. J. Dairy Sci. 92:2931-2946.

Cole, J. B., G. R. Wiggans, L. Ma, T. S. Sonstegard, T. J. Lawlor, B. A. Crooker, C. P. Van Tassell, J. Yang, S. Wang, L. K. Matukumalli, and Y. Da. 2011. Genome-wide association analysis of thirty one production, health, reproduction and body conformation traits in contemporary U.S. Holstein cows. BMC Genomics 12:408. https://doi.org/10.1186/1471-2164-12-408.

Connor, E. E., R. L. Baldwin, M. P. Walker, S. E. Ellis, C. Li, S. Kahl, H. Chung, and R. W. Li. 2014. Transcriptional regulators transforming growth factor- $\beta 1$ and estrogen-related receptor- $\alpha$ identified as putative mediators of calf rumen epithelial tissue development and function during weaning. J. Dairy Sci. 97:4193-4207. https://doi.org/10.3168/jds.2013-7471.

Connor, E. E., J. L. Hutchison, H. D. Norman, K. M. Olson, C. P. Van Tassell, J. M. Leith, and R. L. Baldwin VI. 2013. Use of residual feed intake in Holsteins during early lactation shows potential to improve feed efficiency through genetic selection. J. Anim. Sci. 91:3978-3988. https://doi.org/10.2527/jas.2012-5977.

Connor, E. E., S. Kahl, T. H. Elsasser, J. S. Parker, R. W. Li, C. P. Van Tassell, R. L. Baldwin, and S. M. Barao. 2010. Enhanced mitochondrial complex gene function and reduced liver size may mediate improved feed efficiency of beef cattle during compensa- 
tory growth. Funct. Integr. Genomics 10:39-51. https://doi.org/10 $.1007 / \mathrm{s} 10142-009-0138-7$.

Crews, D. H. Jr. 2005. Genetics of efficient feed utilization and national cattle evaluation: A review. Genet. Mol. Res. 4:152-165.

de Camargo, G. M. F., R. R. Aspilcueta-Borquis, M. R. S. Fortes, R. Porto-Neto, D. F. Cardoso, D. J. A. Santos, S. A. Lehnert, A. Reverter, S. S. Moore, and H. Tonhati. 2015. Prospecting major genes in dairy buffaloes. BMC Genomics 16:872. https://doi.org/ 10.1186/s12864-015-1986-2.

de Haas, Y., J. E. Pryce, M. P. L. Calus, E. Wall, D. P. Berry, P. Løvendahl, N. Krattenmacher, F. Miglior, K. Weigel, D. Spurlock, K. A. Macdonald, B. Hulsegge, and R. F. Veerkamp. 2015. Genomic prediction of dry matter intake in dairy cattle from an international data set consisting of research herds in Europe, North America, and Australasia. J. Dairy Sci. 98:6522-6534. https://doi org/10.3168/jds.2014-9257.

Derynck, R., and Y. E. Zhang. 2003. Smad-dependent and Smad-independent pathways in TGF- $\beta$ family signalling. Nature 425:577-584

Ehrhardt, R. A., A. Foskolos, S. L. Giesy, S. R. Wesolowski, C. S. Krumm, W. R. Butler, S. M. Quirk, M. R. Waldron, and Y. R. Boisclair. 2016. Increased plasma leptin attenuates adaptive metabolism in early lactating dairy cows. J. Endocrinol. 229:145-157. https://doi.org/10.1530/JOE-16-0031.

Elolimy, A. A., J. M. Arroyo, F. Batistel, M. A. Iakiviak, and J. J. Loor. 2018. Association of residual feed intake with abundance of ruminal bacteria and biopolymer hydrolyzing enzyme activities during the peripartal period and early lactation in Holstein dairy cows. J. Anim. Sci. Biotechnol. 9:43. https://doi.org/10.1186/ s40104-018-0258-9.

Essner, R.A., A.G. Smith, A.A. Jamnik, A.R. Ryba, Z.D. Trutner, and M.E. Carter. 2017. AgRP neurons can increase food intake during conditions of appetite suppression and inhibit anorexigenic parabrachial neurons. J. Neurosci. 37:8678-8687.

European Commission. 2018. EU dairy farms report based on 2016 FADN data. Accessed March 12, 2019. http://ec.europa.eu/ agriculture/rica/pdf/Dairy_report_2016.pdf.

Fang, L., G. Sahana, P. Ma, G. Su, Y. Yu, S. Zhang, M. S. Lund, and P. Sørensen. 2017. Use of biological priors enhances understanding of genetic architecture and genomic prediction of complex traits within and between dairy cattle breeds. BMC Genomics 18:604. https://doi.org/10.1186/s12864-017-4004-Z

Fecteau, R. E., J. Kong, A. Kresak, W. Brock, Y. Song, H. Fujioka, R. Elston, J. E. Willis, J. P. Lynch, S. D. Markowitz, K. Guda, and A. Chak. 2016. Association between germline mutation in VSIG101 and familial Barrett neoplasia. JAMA Oncol. 2:1333-1339.

Ferraretto, L. F., R. D. Shaver, and S. J. Bertics. 2012. Effect of dietary supplementation with live-cell yeast at two dosages on lactation performance, ruminal fermentation, and total-tract nutrient digestibility in dairy cows. J. Dairy Sci. 95:4017-4028. https://doi .org/10.3168/jds.2011-5190.

Fontoura, A. B. P., Y. R. Montanholi, M. Diel de Amorim, R. A. Foster, T. Chenier, and S. P. Miller. 2016. Associations between feed efficiency, sexual maturity and fertility-related measures in young beef bulls. Animal 10:96-105. https://doi.org/10.1017/ S1751731115001925.

Forni, S., I. Aguilar, and I. Misztal. 2011. Different genomic relationship matrices for single-step analysis using phenotypic, pedigree and genomic information. Genet. Sel. Evol. 43:1. https://doi.org/ 10.1186/1297-9686-43-1

Funderburgh, J. L. 2000. Keratan sulfate: Structure, biosynthesis, and function. Glycobiology 10:951-958.

Hardie, L. C., M. J. VandeHaar, R. J. Tempelman, K. A. Weigel, L. E. Armentano, G. R. Wiggans, R. F. Veerkamp, Y. de Haas, M. P. Coffey, E. E. Connor, M. D. Hanigan, C. Staples, Z. Wang, J. C. M. Dekkers, and D. M. Spurlock. 2017. The genetic and biological basis of feed efficiency in mid-lactation Holstein dairy cows. J. Dairy Sci. 100:9061-9075. https://doi.org/10.3168/jds.2017-12604.

Hayes, B. 2013. Overview of statistical methods for genome-wide association studies (GWAS). Pages 149-169 in Genome-Wide Association Studies and Genomic Prediction. C. Gondro, J. van der Werf, and B. Hayes, ed. Humana Press, Totowa, NJ.
He, M., K. L. Perfield, H. B. Green, and L. E. Armentano. 2012. Effect of dietary fat blend enriched in oleic or linoleic acid and monensin supplementation on dairy cattle performance, milk fatty acid profiles, and milk fat depression. J. Dairy Sci. 95:1447-1461. https:// doi.org/10.3168/jds.2011-4635.

He, M., M. Xu, B. Zhang, J. Liang, P. Chen, J. Lee, T. A. Johnson, H. Li, X. Yang, J. Dai, L. Liang, L. Gui, Q. Qi, J. Huang, Y. Li, L. S. Adair, T. Aung, Q. Cai, C. Cheng, C. C. Khor, B. Kim, H. T. Kim, M. Kubo, J. Lee, J. Lee, N. R. Lee, R. Li, J. Li, J. Liu, J. Longe, W. Lu, X. Lu, X. Miao, Y. Okada, R. T. Ong, G. Qiu, M. Seielstad, X. Sim, H. Song, F. Takeuchi, T. Tanaka, M. Liao, M. Yokota, T. Young, X. Zhang, B. Han, X. Shu, E. S. Tai, and T. Wu. 2015. Meta-analysis of genome-wide association studies of adult height in East Asians identifies 17 novel loci. Hum. Mol. Genet. 24:1791-1800. https://doi.org/10.1093/hmg/ddu583.

Hou, Y., D. M. Bickhart, H. Chung, J. L. Hutchison, H. D. Norman, E. E. Connor, and G. E. Liu. 2012. Analysis of copy number variations in Holstein cows identify potential mechanisms contributing to differences in residual feed intake. Funct. Integr. Genomics 12:717-723. https://doi.org/10.1007/s10142-012-0295-y.

Houseknecht, K. L., C. A. Baile, R. L. Matteri, and M. E. Spurlock. 1998. The biology of leptin: A review. J. Anim. Sci. 76:1405-1420.

Hurley, A. M., N. López-Villalobos, S. McParland, E. Lewis, E. Kennedy, M. O'Donovan, J. L. Burke, and D. P. Berry. 2017. Genetics of alternative definitions of feed efficiency in grazing lactating dairy cows. J. Dairy Sci. 100:5501-5514. https://doi.org/10.3168/ jds.2016-12314.

Jewell, K. A., C. A. McCormick, C. L. Odt, P. J. Weimer, and G. Suen. 2015. Ruminal bacterial community composition in dairy cows is dynamic over the course of two lactations and correlates with feed efficiency. Appl. Environ. Microbiol. 81:4697-4710. https://doi.org/10.1128/AEM.00720-15.

Koch, R. M., L. A. Swiger, D. Chambers, and K. E. Gregory. 1963 Efficiency of feed use in beef cattle. J. Anim. Sci. 22:486-494.

Kohno, D., S. Lee, M.J. Harper, K.W. Kim, H. Sone, T. Sasaki, T. Kitamura, G. Fan, and J.K. Elmquist. 2014. Dnmt3a in Sim1 neurons is necessary for normal energy homeostasis. J. Neurosci. 34:15288-15296.

Kolath, W. H., M. S. Kerley, J. W. Golden, and D. H. Keisler. 2006. The relationship between mitochondrial function and residual feed intake in Angus steers. J. Anim. Sci. 84:861-865.

Kong, B.-W., K. Lassiter, A. Piekarski-Welsher, S. Dridi, A. ReverterGomez, N. J. Hudson, and W. G. Bottje. 2016. Proteomics of breast muscle tissue associated with the phenotypic expression of feed efficiency within a pedigree male broiler line: I. Highlight on mitochondria. PLoS One 11:e0155679. https://doi.org/10.1371/ journal.pone.0155679.

Krahn, D. D., B. A. Gosnell, A. S. Levine, and J. E. Morley. 1984. Effects of calcitonin gene-related peptide on food intake. Peptides 5:861-864. https://doi.org/10.1016/0196-9781(84)90107-4.

Lamon, S., M. A. Wallace, B. Léger, and A. P. Russell. 2009. Regulation of STARS and its downstream targets suggest a novel pathway involved in human skeletal muscle hypertrophy and atrophy. J. Physiol. 587:1795-1803. https://doi.org/10.1113/jphysiol.2009 .168674 .

Lee, A. S. Y., P. J. Kranzusch, and J. H. D. Cate. 2015. eIF3 targets cell-proliferation messenger RNAs for translational activation or repression. Nature 522:111-114. https://doi.org/10.1038/ nature 14267.

Legarra, A., I. Aguilar, and I. Misztal. 2009. A relationship matrix including full pedigree and genomic information. J. Dairy Sci. 92:4656-4663. https://doi.org/10.3168/jds.2009-2061.

Li, B., B. Berglund, W. F. Fikse, J. Lassen, M. H. Lidauer, P. Mäntysaari, and P. Løvendahl. 2017. Neglect of lactation stage leads to naive assessment of residual feed intake in dairy cattle. J. Dairy Sci. 100:9076-9084. https://doi.org/10.3168/jds.2017-12775.

Li, B., W. F. Fikse, P. Løvendahl, J. Lassen, M. H. Lidauer, P. Mäntysaari, and B. Berglund. 2018. Genetic heterogeneity of feed intake, energy-corrected milk, and body weight across lactation in primiparous Holstein, Nordic Red, and Jersey cows. J. Dairy Sci. 101:10011-10021. https://doi.org/10.3168/jds.2018-14611. 
Liinamo, A.-E., P. Mäntysaari, M. H. Lidauer, and E. A. Mäntysaari. 2015. Genetic parameters for residual energy intake and energy conversion efficiency in Nordic Red dairy cattle. Acta Agric. Scand. A Anim. Sci. 65:63-72. https://doi.org/10.1080/09064702 2015.1070897.

Lin, A. H.-M., B. R. Hamaker, and B. L. J. Nichols. 2012. Direct starch digestion by sucrase-isomaltase and maltase-glucoamylase. J. Pediatr. Gastroenterol. Nutr. 55(Suppl. 2):S43-S45.

Loor, J. J., H. M. Dann, N. A. J. Guretzky, R. E. Everts, R. Oliveira, C. A. Green, N. B. Litherland, S. L. Rodriguez-Zas, H. A. Lewin, and J. K. Drackley. 2006. Plane of nutrition prepartum alters hepatic gene expression and function in dairy cows as assessed by longitudinal transcript and metabolic profiling. Physiol. Genomics 27:29-41. https://doi.org/10.1152/physiolgenomics.00036.2006.

Lu, Y., M. J. Vandehaar, D. M. Spurlock, K. A. Weigel, L. E. Armentano, E. E. Connor, M. Coffey, R. F. Veerkamp, Y. de Haas, C. R. Staples, Z. Wang, M. D. Hanigan, and R. J. Tempelman. 2018. Genome-wide association analyses based on a multiple-trait approach for modeling feed efficiency. J. Dairy Sci. 101:3140-3154. https://doi.org/10.3168/jds.2017-13364.

Lu, Y., M. J. Vandehaar, D. M. Spurlock, K. A. Weigel, L. E. Armentano, C. R. Staples, E. E. Connor, Z. Wang, N. M. Bello, and R. J. Tempelman. 2015. An alternative approach to modeling genetic merit of feed efficiency in dairy cattle. J. Dairy Sci. 98:6535-6551. https://doi.org/10.3168/jds.2015-9414.

Ma, C. A., J. R. Stinson, Y. Zhang, J. K. Abbott, M. A. Weinreich, P. J. Hauk, P. R. Reynolds, J. J. Lyons, C. G. Nelson, E. Ruffo, B. Dorjbal, S. Glauzy, N. Yamakawa, S. Arjunaraja, K. Voss, J. Stoddard, J. Niemela, Y. Zhang, S. D. Rosenzweig, J. J. McElwee, T. DiMaggio, H. F. Matthews, N. Jones, K. D. Stone, A. Palma, M. Oleastro, E. Prieto, A. R. Bernasconi, G. Dubra, S. Danielian, J. Zaiat, M. A. Marti, B. Kim, M. A. Cooper, N. Romberg, E. Meffre, E. W. Gelfand, A. L. Snow, and J. D. Milner. 2017. Germline hypomorphic CARD11 mutations in severe atopic disease. Nat. Genet. 49:1192-1201. https://doi.org/10.1038/ng.3898.

Manzanilla-Pech, C. I. V., R. F. Veerkamp, R. J. Tempelman, M. L. van Pelt, K. A. Weigel, M. VandeHaar, T. J. Lawlor, D. M. Spurlock, L. E. Armentano, C. R. Staples, M. Hanigan, and Y. De Haas. 2016. Genetic parameters between feed-intake-related traits and conformation in 2 separate dairy populations - The Netherlands and United States. J. Dairy Sci. 99:443-457. https://doi.org/ 10.3168/jds.2015-9727.

Misztal, I. 2013. BLUPF90 - A flexible mixed model program in Fortran 90. http://nce.ads.uga.edu/wiki/lib/exe/fetch.php?media= blupf90.pdf.

Mohan, M., J. R. Malayer, R. D. Geisert, and G. L. Morgan. 2001. Expression of retinol-binding protein messenger RNA and retinoic acid receptors in preattachment bovine embryos. Mol. Reprod. Dev. 60:289-296. https://doi.org/10.1002/mrd.1090.

Morota, G., F. Peñagaricano, J. L. Petersen, D. C. Ciobanu, K. Tsuyuzaki, and I. Nikaido. 2015. An application of MeSH enrichment analysis in livestock. Anim. Genet. 46:381-387. https://doi.org/ 10.1111/age.12307.

Nkrumah, J. D., E. L. Sherman, C. Li, E. Marques, D. H. Crews Jr., R. Bartusiak, B. Murdoch, Z. Wang, J. A. Basarab, and S. S. Moore. 2007. Primary genome scan to identify putative quantitative trait loci for feedlot growth rate, feed intake, and feed efficiency of beef cattle. J. Anim. Sci. 85:3170-3181.

Okada, Y., Y. Kamatani, A. Takahashi, K. Matsuda, N. Hosono, H. Ohmiya, Y. Daigo, K. Yamamoto, and M. Kubo. 2010. A genomewide association study in 19633 Japanese subjects identified LHX3-QSOX2 and IGF1 as adult height loci. Hum. Mol. Genet. 19:2303-2312. https://doi.org/10.1093/hmg/ddq091.

Patel, N., E. C. Brinkman-Van der Linden, S. W. Altmann, K. Gish, S. Balasubramanian, J. C. Timans, D. Peterson, M. P. Bell, J. F. Bazan, A. Varki, and R. A. Kastelein. 1999. OB-BP1/Siglec-6. a leptin- and sialic acid-binding protein of the immunoglobulin superfamily. J. Biol. Chem. 274:22729-22738.

Patience, J. F., M. C. Rossoni-Serão, and N. A. Gutiérrez. 2015. A review of feed efficiency in swine: Biology and application. J. Anim. Sci. Biotechnol. 6:33. https://doi.org/10.1186/s40104-015-0031-2.
Perland, E., E. Lekholm, M. M. Eriksson, S. Bagchi, V. Arapi, and R. Fredriksson. 2016. The putative SLC transporters Mfsd5 and Mfsd11 are abundantly expressed in the mouse brain and have a potential role in energy homeostasis. PLoS One 11:e0156912.

Pryce, J. E., O. Gonzalez-Recio, G. Nieuwhof, W. J. Wales, M. P. Coffey, B. J. Hayes, and M. E. Goddard. 2015. Hot topic: Definition and implementation of a breeding value for feed efficiency in dairy cows. J. Dairy Sci. 98:7340-7350. https://doi.org/10.3168/ jds.2015-9621.

Rohde, P. D., D. Demontis, B. C. D. Cuyabano, A. D. Børglum, and P. Sørensen. 2016. Covariance association test (CVAT) identifies genetic markers associated with schizophrenia in functionally associated biological processes. Genetics 203:1901-1913.

Rohde, P. D., I. F. S. Ørensen, and P. S. Ørensen. 2018. qgg: An $\mathrm{R}$ package for large-scale quantitative genetic analyses. bioRxiv 503631. https://doi.org/10.1101/503631.

Salleh, M. S., G. Mazzoni, J. K. Höglund, D. W. Olijhoek, P. Lund, P. Løvendahl, and H. N. Kadarmideen. 2017. RNA-Seq transcriptomics and pathway analyses reveal potential regulatory genes and molecular mechanisms in high- and low-residual feed intake in Nordic dairy cattle. BMC Genomics 18:258. https://doi.org/10 $.1186 / \mathrm{s} 12864-017-3622-9$.

Schmid, M., and J. Bennewitz. 2017. Invited review: Genome-wide association analysis for quantitative traits in livestock-A selective review of statistical models and experimental designs. Arch. Tierzucht 60:335-346. https://doi.org/10.5194/aab-60-335-2017.

Spurlock, D. M., J. C. M. Dekkers, R. Fernando, D. A. Koltes, and A. Wolc. 2012. Genetic parameters for energy balance, feed efficiency, and related traits in Holstein cattle. J. Dairy Sci. 95:5393-5402. https://doi.org/10.3168/jds.2012-5407.

Stepensky, P., B. Keller, M. Buchta, A.-K. Kienzler, O. Elpeleg, R. Somech, S. Cohen, I. Shachar, L. A. Miosge, M. Schlesier, I. Fuchs, A. Enders, H. Eibel, B. Grimbacher, and K. Warnatz. 2013. Deficiency of caspase recruitment domain family, member 11 (CARD11), causes profound combined immunodeficiency in human subjects. J. Allergy Clin. Immunol. 131:477-485.e1. https:// doi.org/10.1016/j.jaci.2012.11.050.

Tempelman, R. J., D. M. Spurlock, M. Coffey, R. F. Veerkamp, L. E. Armentano, K. A. Weigel, Y. de Haas, C. R. Staples, E. E. Connor, Y. Lu, and M. J. VandeHaar. 2015. Heterogeneity in genetic and nongenetic variation and energy sink relationships for residual feed intake across research stations and countries. J. Dairy Sci. 98:2013-2026. https://doi.org/10.3168/jds.2014.8510.

USDA. 2018. Milk cost-of-production estimates - 2016 base, milk cost of production estimates. Accessed February 10, 2018. https://www .ers.usda.gov/data-products/milk-cost-of-production-estimates/ milk-cost-of-production-estimates/\#Milk Cost-of-Production Estimates-2016 Base.

VandeHaar, M. J., L. E. Armentano, K. Weigel, D. M. Spurlock, R. J. Tempelman, and R. Veerkamp. 2016. Harnessing the genetics of the modern dairy cow to continue improvements in feed efficiency. J. Dairy Sci. 99:4941-4954. https://doi.org/10.3168/jds .2015-10352.

VanRaden, P. M. 2008. Efficient methods to compute genomic predictions. J. Dairy Sci. 91:4414-4423. https://doi.org/10.3168/jds 2007-0980.

VanRaden, P. M., J. R. O'Connell, E. E. Connor, M. J. Vandehaar, R. J. Tempelman, and K. A. Weigel. 2018. Including feed intake data from U.S. Holsteins in genomic prediction. Page 125 in Proc. World Congress on Genetics Applied to Livestock Production, New Zealand. Biology: Feed Intake and Efficiency 1. World Congress on Genetics Applied to Livestock Production Digital Archive, New Zealand. http://www.wcgalp.org/proceedings/2018/including-feed -intake-data-us-holsteins-genomic-prediction.

VanRaden, P. M., M. E. Tooker, J. R. O'Connell, J. B. Cole, and D. M. Bickhart. 2017. Selecting sequence variants to improve genomic predictions for dairy cattle. Genet. Sel. Evol. 49:32. https://doi .org/10.1186/s12711-017-0307-4.

von Gunten, S., and B. S. Bochner. 2008. Basic and clinical immunology of Siglecs. Ann. N. Y. Acad. Sci. 1143:61-82. https://doi.org/ 10.1196/annals.1443.011. 
Wang, H., I. Misztal, I. Aguilar, A. Legarra, R. L. Fernando, Z. Vitezica, R. Okimoto, T. Wing, R. Hawken, and W. M. Muir. 2014. Genome-wide association mapping including phenotypes from relatives without genotypes in a single-step (ssGWAS) for 6-week body weight in broiler chickens. Front. Genet. 5:134. https://doi .org/10.3389/fgene.2014.00134.

Wang, H., I. Misztal, I. Aguilar, A. Legarra, and W. M. Muir. 2012. Genome-wide association mapping including phenotypes from relatives without genotypes. Genet. Res. (Camb.) 94:73-83. https:// doi.org/10.1017/S0016672312000274.

Wendel, M., Y. Sommarin, and D. Heinegård. 1998. Bone matrix proteins: Isolation and characterization of a novel cell-binding keratan sulfate proteoglycan (osteoadherin) from bovine bone. J. Cell Biol. 141:839-847.
Wiggans, G. R., T. A. Cooper, P. M. VanRaden, C. P. Van Tassell, D. M. Bickhart, and T. S. Sonstegard. 2016. Increasing the number of single nucleotide polymorphisms used in genomic evaluation of dairy cattle. J. Dairy Sci. 99:4504-4511. https://doi.org/10.3168/ jds.2015-10456.

Wolc, A., J. Arango, T. Jankowski, P. Settar, J. E. Fulton, N. P. O. Sullivan, R. Fernando, D. J. Garrick, and J. C. M. Dekkers. 2013 Pedigree and genomic analyses of feed consumption and residual feed intake in laying hens. Poult. Sci. 92:2270-2275.

Zhang, J., R. Yan, C. Wu, H. Wang, G. Yang, Y. Zhong, Y. Liu, L. Wan, and A. Tang. 2018. Spermatogenesis-associated 48 is essential for spermatogenesis in mice. Andrologia 50:e13027. https://doi .org/10.1111/and.13027. 